\title{
PARA \\ UMA \\ ESTÉTICA \\ DA ERRÂNCIA: \\ O CORPO, \\ A DANÇA \\ E A ARTE
}

\section{PARA UNA ESTÉTICA DE LA ERRANCIA: EL CUERPO, EL BAILE Y EL ARTE}

FOR AN AESTHETICS OF THE WANDERINGS: THE BODY, THE DANCE, AND THE ART

\author{
João Flávio de Almeida* \\ Universidade Federal de São Carlos \\ Dantielli Assumpção Garcia** \\ Universidade Estadual do Oeste do Paraná
}

\begin{abstract}
RESUMO: O presente artigo tem por objetivo investigar alguns questionamentos do campo da Estética da Arte no interior da Teoria da Linguagem de Michel Pêcheux, propondo, assim, uma Estética Pecheutiana. Buscaremos em seus textos por referências diretas e indiretas que permitam lançarmos as bases para uma nova estética, provisoriamente chamada de Estética da Errância, procurando por fundamentos que permitam algum esboço da arte no seu sentido mais amplo. Na intenção de vermos o funcionamento da Estética da Errância, tomaremos como ponto de discussão a dança e as possíveis linguagens produzidas por esse corpo em texto: se sentidos em deslocamento ou sentidos em suspensão, logo, errantes.
\end{abstract}

PALAVRAS-CHAVE: Estética da Arte. Errância. Dança. Pêcheux.

RESUMEN: Este artículo tiene como objetivo investigar algunas preguntas sobre el campo de la Estética del Arte desde la teoría del lenguaje de Michel Pêcheux, proponiendo así una estética Pecheutiana. Buscamos en sus textos por referencias directas e indirectas que permitan sentar las bases de una nueva estética, denominada, provisionalmente, como Estética de la Errancia, en busca de bases

\footnotetext{
* Graduação em Comunicação Social. Mestre em Ciência, Tecnologia e Sociedade (CTS - UfSCar), e doutorando pelo mesmo programa. Pesquisa: Estéticada Arte em Pêcheux. Bolsista CAPES. E-mail: joaoflaviodealmeida@gmail.com.

** Graduação em Licenciatura em Letras pela Universidade Estadual Paulista Júlio de Mesquita Filho (2005). Mestrado (2008) e doutorado (2011) em Estudos Linguísticos pela mesma universidade. Pós-Doutorado na Faculdade de Filosofia, Ciências e Letras de Ribeirão Preto (USP / 2013-2015), Pós-Doutoranda no Programa de Pós-Graduação em Letras na Universidade Estadual do Oestedo Paraná (UNIOESTE). BolsistaPNPD/CAPES. E-mail: dantielligarcia@gmail.com.
} 
que permiten algún esbozo del arte en su sentido más amplio. Con el fin de ver el funcionamiento de la Estética de la Errancia, tomaremos como punto de discusión la danza y los posibles lenguajes producidos por este cuerpo en texto: si sentidos deslizantes o sentidos suspendidos, errantes.

PALABRAS CLAVE: Estética del arte. Errancia. Bailar. Pêcheux.

ABSTRACT: This article aims to investigate some art Aesthetic issues within Michel Pêcheux's language theory. We seek in his texts direct and indirect references that allow us to lay the foundation for new aesthetics, provisionally called Aesthetics of Wandering, looking for foundations that allow art sketch in its broadest sense. In order to see the operation of the Aesthetics of Wandering, we will take dance and the possible languages produced by this body into text: if felt in displacement, or felt in suspension, wandering. KEYWORDS: Art Aesthetics. Aesthetics Wandering. Dance. Pêcheux.

\section{INTRODUÇÃO}

Começamos este texto nos indagando sobre o que é a arte. Falamos de um campo? De uma relação metafísica entre a humanidade e as ideias por trás das coisas? Falamos de uma manifestação autônoma ou socialmente determinada? Muitas são as dúvidas que margeiam o fazer artístico, muitos são seus lugares e plurais os seus dizeres. E o que propomos neste artigo é dizer mais um dizer: uma nova perspectiva para se olhar para as artes, um novo ponto de vista, lugar de vista: errante.

Há mais de dois milênios tais questionamentos sobre a arte trazem inquietações para pensadores de diversos campos, e o ponto de partida, muitas vezes, foi/é a arte da Grécia antiga. Já naqueles dias, Platão, Aristóteles e outros discutiam questões referentes à definição da arte, seus limites, seu papel político e social, sua autonomia e heteronomia e outros temas que margeiam essa questão (JIMENEZ, 1999). Contudo, foi somente no século XVIII que a estética da arte alcançou sua autonomia enquanto campo de estudos. Tal autonomia decorreu da liberdade que a própria arte alcançou no século XIV, quando principiou sua ruptura com o artesanato fabril (até então a arte era meramente um trabalho técnico e racional do artesão) para então carregar sentidos de outras ordens, não mais exclusivamente práticas e materiais, mas transcendentais e universais. Foi esse movimento que possibilitou o surgimento de grandes criadores de arte - livres para uma arte igualmente livre (MUNIZ, 2010).

Desde então, grandes filósofos se dedicaram ao assunto. Kant (2002) e Hegel (2011) trouxeram para a estética as primeiras contradições e dicotomias que fundamentaram discussões posteriores. Nietzsche (1992), Diderot (1993), Heidegger (1992) e outros tantos dos séculos XIX e XX também se aplicaram nos estudos estéticos sobre a arte e os resultados são surpreendentemente diversos e quase sempre contraditórios (JIMENEZ, 1999, p. 81).

Tomando então como ponto de partida a pergunta: o que é a arte?, nos defrontamos com outra que fundamenta o percurso deste artigo: é possível considerar teoricamente uma estética da arte a partir de Michel Pêcheux?

Hegel (2011) aponta que a constituição da estética como disciplina autônoma pressupõe que tal conjunto de teorias e conceitos possa ser aplicado igualmente a diversas formas de artes, quer se trate da pintura, da escultura, da música, poesia etc. Por suposto, isso não significa que tais artes devam ser assimiladas umas às outras, visto que sabemos perfeitamente que cada arte solicita os sentidos (fisiológicos) de uma maneira particular, o que, por sua vez, trabalha os sentidos (discursivos) também de forma peculiar. Por isso, segundo Hegel, convém a uma teoria estética que ela corresponda a um conceito ao mesmo tempo unitário, mas que respeite as diferenças de cada manifestação artística, ou seja, precisa ser una e múltipla ao mesmo tempo. E será essa premissa que guiará este trabalho: lançar as bases para uma estética da arte, a partir de Pêcheux, que possa levar contribuições para diversas formas de manifestações artísticas. Segundo o esteta Muniz (2010, p. 62), a melhor maneira de conceber essa unidade múltipla das artes é insistir numa especificidade irredutível. Se as artes forem separadas, é preciso poder ligar sua diversidade a uma noção mais geral, isto é, subsumi-las a um conceito universal. O que se chama "singularização da arte" corresponde à ideia de que a "atividade artística" engloba as diferentes práticas artísticas sob um mesmo substantivo singular: "arte" (JIMENEZ, 1999, p. 95). 
Assim, para se falar de uma estética pecheutiana, teremos que buscar, no autor, pelo "irredutível” comum às manifestações artísticas, ou seja, buscar pela natureza da arte e verificar seu delineamento e funcionamento a partir dos conceitos pecheutianos. O objetivo desta proposta é fundar um percurso teórico que possa fundamentar discussões a respeito da Arte, e não apenas desenvolver análises sobre materialidades discursivas específicas (como o verbal, o não-verbal, a dança, o cinema, a música etc.), nosso objetivo será olhar para a linguagem artística que fundamenta essas e outras manifestações artísticas.

Desse modo, não temos por objetivo apenas trazer discussões estéticas para o interior de uma análise discursiva específica (na forma de memória), mas sim fundarmos, a partir dos próprios conceitos de Pêcheux, um novo arcabouço teórico que fundamente uma nova forma de olhar para as artes, "artes plurais e diversas", como apontou Hegel. Nossa proposta é, portanto, levar algumas ideias de Michel Pêcheux para o campo das artes, bem como tornar a teoria pecheutiana fecunda e aberta a novas perspectivas. Para este trabalho, no qual trabalharemos a dança, o corpo passa a ter uma importante significação. O corpo, como veremos, é a materialidade do sujeito, lugar de dizer e de dizeres. E a dança é uma das mais belas formas de fazer do corpo uma linguagem viva e fecunda. Contudo uma pergunta iminente nos tangencia: qualquer movimento ritmado do corpo é, a priori, dança? Ou ainda: toda dança é, essencialmente, uma atividade artística? Esse duplo questionamento é a chave deste artigo, pois se à primeira pergunta respondêssemos afirmativamente teríamos que assumir, por exemplo, que qualquer apanhado desordenado de letras escritas já bastaria para constituir um texto ou que qualquer soma disforme de sons consistiria em música. E se respondêssemos afirmativamente à segunda pergunta, então, teríamos que admitir que qualquer texto é poesia ou que qualquer música é arte.

Essa relativização e indefinição da arte se mostra uma discussão muito atual e complexa. Ora, qualquer filme, qualquer pintura, qualquer fotografia, qualquer escultura, enfim, é arte? E quando se vê a apropriação do termo "arte" por outros campos, tais como "a arte de bem cuidar", pela enfermagem (FERREIRA, 2011), ou "a arte de bem construir uma casa" pelos engenheiros (SHAPIRO, 2013), ou ainda o título de artista sendo requisitado por acrobatas de circo, publicitários, estilistas, grafiteiros, tipógrafos, chefes de cozinha e muitos outros? Todo mundo quer ser artista, embora exista certa resistência em se conferir o atributo da "arte" a um cantor de sertanejo universitário (SANTOS, 2011) ou aos dançarinos de break dance.

Assim, por considerarmos dentro da Análise do Discurso (AD) que o corpo é a materialidade do sujeito e que o corpo já fala antes mesmo de nascer, o objetivo deste artigo é mirar a linguagem produzida por um corpo em dança com o intuito de ver o movimento de transformação desse movimento/fala em linguagem artística (ou não). Por fim, nosso olhar, neste artigo, é para o corpo em dança e para a dança em arte. Dizeres.

\section{A ARTE E A LINGUAGEM NOTURNA: INCONCLUSÃO DOS DIZERES}

A aproximação da linguagem e da arte sempre foi mote de estudos de diversos estetas. Muitos propuseram que a arte é a poetização de um objeto: uma escultura qualquer se distinguiria de uma artística quando essa última fosse "poetizada" (JIMENEZ, 1999), ou seja, quando a linguagem que lhe fundamentasse fosse poetizada e recebesse significados para além de sua função prática (MUNIZ, 2010, p. 44). Esse funcionamento da obra de arte nos conduz ao primeiro grande questionamento do campo da estética que podemos trazer para esta proposta de "Estética Pecheutiana": o que é a arte e o que é a linguagem? Onde começa e termina cada um desses conceitos? Onde se convergem e quando se distanciam? Compreendendo como uma materialidade artística qualquer fala e dotando sua linguagem de opacidade, podemos olhar a dimensão poética de uma obra e observar seu caráter artístico.

Pêcheux, em sua obra co-escrita com Gadet, A língua Inatingível (PÊCHEUX; GADET, 2004), aborda a questão da linguagem poética ao fazer um contraponto à teoria de Milner sobre a linguagem e o real da língua. Tal diálogo traz várias pistas sobre a forma com que Pêcheux concebe a poesia em seu sistema, dando fundamentos para uma discussão estética - para além das discussões de ideologia e assujeitamento.

Em O Amor da Língua (MILNER, 1987), o autor confere um lugar destacado - separado e privilegiado - para o que ele chama de linguagem poética, como se esta existisse nos limites das dobras da língua dando contorno e lógica à língua. Pêcheux, ao contrário dele, coloca a "linguagem poética" no mesmo patamar de toda a linguagem, retirando a poesia de qualquer lugar privilegiado que se

Fórum linguistic., Florianópolis, v.14, n.1, p.1839-1848, jan./mar.2017. 
possa colocá-la. E isso se dá pelo simples fato de que a linguagem poética faz uso dos mesmos mecanismos da linguagem genérica e só existe por causa da linguagem. É justamente a anulação dessa distinção estrutural que destaca a "linguagem poética" das demais que também leva a teoria pecheutiana a assumir as falhas da língua:

Não há poesia porque o que afeta e corrompe o princípio da univocidade na língua não é localizável nela: o equívoco aparece exatamente como o ponto em que o impossível (linguístico) vem aliar-se à contradição (histórica); o ponto em que a língua atinge a história (PÊCHEUX; GADET, 2004, p.64).

Pêcheux argumenta, portanto, que a mesma língua pode ser usada pelo cientista, pelo poeta e pelo louco, logo, toda ela pode ser poética, ou científica, ou ainda totalmente ilógica e absurda. Para ele, o único elemento discursivo capaz de fender e isolar essas "formas" de linguagem é o sujeito discursivo - e, neste caso, falamos do sujeito poeta e do sujeito leitor de poesia. Em última instância, em Pêcheux, não existe um lugar especial e mágico para a arte, como romantizam tantos estetas; o poético é apenas "[...] um deslizamento inerente a toda linguagem [...]" (PÊCHEUX; GADET, 2004, p. 58). Assim, a poesia não está na língua, mas no sujeito da criação e no sujeito da leitura (levando em consideração que a criação e a leitura não são, na $\mathrm{AD}$, processos distintos, mas amalgamados). A língua funciona tão somente como materialidade (fundamento) do discurso poético; e o poeta, por sua vez, é aquele que leva as propriedades da linguagem até seu limite - mas ele ainda o faz com as propriedades da própria língua.

Aprofundando essa análise das propriedades da língua, Pêcheux faz duas afirmações que são reveladoras para a constituição desse olhar estético que propomos.

O que faz aqui irrupção na linguística [...] refere-se precisamente à relação entre o diurno e o noturno, entre a ciência e a poesia (ou até a loucura) (PÊCHEUX; GADET, 2004, p. 58).

É na trama imaginária de uma teoria que se negocia a relação com a loucura: quando, hoje em dia, decidimos lançar a ciência contra a loucura, começamos por fazer da ciência uma lógica oposta à não-lógica da loucura; esquecemos, assim, que a loucura (e a poesia) fazem também um certo uso da língua, são igualmente apreendidas no real (PÊCHEUX; GADET, 2004, p. 63).

Nessas citações, observa-se um efeito parafrástico entre poesia e noturno. Essa reescrita traz uma importante revelação para esta proposta, na medida em que Pêcheux articula poesia com ciência e ciência com diurno. Assim, podemos dizer que poesia é metaforicamente chamada por noturno em oposição à ciência, reescrita por diurno. Indo além, existe ainda uma articulação entre poesia e loucura e, nas palavras do autor, aparece o operador até - "e a poesia (ou até a loucura)" - que, aparentemente, coloca a loucura em um grau para além da poesia, porém, dentro da mesma escala. Mas de que escala está falando Pêcheux?

Nesse momento, o autor parece propor uma escala de estabilidade e regularidade do uso da palavra, todavia, como já foi dito, sem a existência de uma fissura que possa apartar uma linguagem de outra - a não ser o lugar discursivo ocupado pelo sujeito que ali fala. Nessa escala, numa extremidade temos a linguagem científica: a linguagem diurna, ou seja, a linguagem clara, da certeza, da regularidade e da estabilidade; contudo, temos, no outro extremo, a linguagem da loucura, noutras palavras, aquela que não faz sentido na plenitude do noturno, que por ser tão absurda e equívoca, já não faz sentido algum. Nesse entremeio, aponta Pêcheux, figura o espaço da linguagem poética (artística), ou seja, aquela que não tem compromisso com a verdade, com o estável, nem com o seguro. É o fazer linguageiro em que se assume e se enfrenta o medo da instabilidade, dos furos, das derivas, das ambiguidades, das polissemias e dos erros. É o lugar da incerteza, entre a razão e a loucura.

O poético (noturno) tende para o instável e errante por oposição ao científico (diurno), que tende para o lógico e assertivo. A saber, além da linguagem científica, a linguagem filosófica também busca pela coerência e pela estabilidade diurna; assim como a linguagem religiosa e a linguagem jornalística, que pregam a verdade. A linguagem do discurso do entretenimento proveniente da indústria cultural (ADORNO, 1999) também precisa ser clara e assertiva para vender e ser vendida, o que também ocorre com os dizeres dos partidos políticos, com as grandes corporações capitalistas e suas propagandas etc. 
Ora, se a arte fizer uso da linguagem clara, política e ideológica, então não precisamos de arte, porque já temos uma grande variedade de instituições que regulam a sociedade através da linguagem diurna. A arte, para/por não ser ciência, mas arte - faz uso de uma linguagem marginal, situada nos cantos, distante do centro seguro, lógico e claro da linguagem diurna e da tutela da ideologia dominante. Porém, como também já vimos, a plenitude do "não-sentido" seria da ordem da loucura, o que não é o caso. O uso que a arte faz da linguagem situa-se entre os extremos do absurdo e da verdade, situa-se no entremeio da incerteza e da errância. Ao contrário das danças, dos filmes e das músicas da indústria cultural e do entretenimento, que minimiza e nega ao máximo qualquer incerteza da linguagem, a arte aceita e trabalha com os furos da linguagem, suas derivas de sentido e seu caráter polissêmico e ambíguo.

E calcados nesse modelo pecheutiano (a linguagem noturna da arte por oposição à linguagem diurna da ciência) é que propomos, portanto, o estabelecimento do conceito de "Estética da Errância". O errante é aquele que anda sem destino certo, vagueando sem saber exatamente onde vai chegar. Os sentidos da linguagem artística, ao contrário da científica e da indústria do entretenimento, são errantes, vacilantes, incertos e imprecisos. São noturnos, inconclusos, indeterminados e errantes. E aqui chegamos ao ponto central na proposição desta estética: se o poético não possui um lugar especial ou um funcionamento desligado do resto da língua, toda a língua tende para a poesia ou para a ciência a partir da forma com que se usa a linguagem. E neste caso, a medida seria a relação entre o sujeito que toma a palavra e seu comprometimento com uma língua perfeita e acabada ou, ao contrário, em brincar com a incompletude da língua e suas possibilidades. Assim, a Estética da Errância se funda, conceitualmente, na assunção dos erros da linguagem ao invés de sua negação. A linguagem artística é aquela que brinca com a falta fundamental da língua e joga com a impossibilidade de que o sentido seja um, de que se estabeleça e se assente num lugar definitivo. A arte, portanto, deseja e trabalha essa incompletude que desestabiliza, a poesia é justamente a busca pela errância dos sentidos.

\section{NOSSO OLHAR É PARA O CORPO EM DANÇA E PARA A DANÇA EM ARTE}

O corpo fala, ainda que de boca calada: é que o corpo é a materialidade do sujeito. Mas como isso? A materialidade da ideologia é discurso, e do discurso, a língua. A língua é o que cinge (materialmente) ideologia e inconsciente, constituindo o sujeito. E a materialidade do sujeito? Ora, é seu corpo! (ORLANDI, 2012). Mas não vale dividir sujeito e corpo como fez Descartes, com sua alma separada de sua substância extensa: aqui o corpo é o sujeito, é sua materialidade, sua inserção histórica e social na realidade. Sujeito e mundo não se separam.

Antes do corpo havia a carne, essa que passa a corpo por um processo de discursivização, imaginação, espera, educação e administração (ORLANDI, 2012, p. 85). O corpo empírico não nos interessa como à medicina, mas sim sua materialidade enquanto possibilidade discursiva, enquanto materialidade do sujeito.

Sujeito e sentido, se transparentes (ORLANDI, 1996), pareceriam ter gênese indeterminada, como se sempre estivessem aí, perenes e constantes. Contudo, são opacas e efêmeras construções: efeitos da ideologia (ORLANDI, 2012). E quando consideramos corpo e sujeito, dali emergem sentidos que o constituíam/constituem/constituirão antes mesmo de seu nascer, evidenciando que o sujeito não está na origem de si, tampouco dos sentidos; ao contrário, nasce ali, imerso na ideologia. Assim se vê o corpo: materialidade do sujeito, este em relação com a ideologia através de sua materialidade: o discurso; e dele a língua, a história e as condições sociais (ORLANDI, 2012, p.87). Eé justamente porque são incompletos é que sujeito, sentido, história, sociedade, discurso e ideologia estão em movimento numa perene dialética materialista.

A constituição dos sentidos do/no corpo/sujeito se dá numa íntima relação com o espaço físico que o envolve, uma vez que o corpo, como materialidade do sujeito, constitui sua própria inscrição na histórica e na sociedade. É em relação com o espaço que o sujeito escreve em seu corpo e escreve através de seu corpo. E como haveria de ser diferente? Um corpo em relação com o espaço rural significa sentidos outros de um corpo absorvido pela cidade: ferramenta de trabalho, moda, pescaria, shoppings, natureza, cultura etc. Um sujeito praticante de esportes pode ter um corpo semelhante ao de um trabalhador rural, mas a força e os movimentos que 
ambos produzem significam em relação a seus espaços: força pode ser beleza para um e trabalho para outro: interpelação do sujeito pela ideologia (ORLANDI, 2004).

O corpo escreve e se inscreve, fala enquanto é falado, discursiviza enquanto é discursivizado. Sua opacidade revela uma íntima relação com a ideologia enquanto prática que envolve e afeta esse processo de significação do sujeito/corpo, ou seja, é a ideologia que consubstancia a narrativa corporal à narrativa do espaço histórico e social, uma dupla constituição de sentidos: sujeito/corpo, espaço/corpo (ORLANDI, 2012). Vale ressaltar que essa relação não é simétrica, como se uma fosse representação plena do acontecimento da outra. A interpelação do sujeito pela ideologia é assimétrica, uma fissura que engendra uma incompletude fundamental, diga-se essencial, pois é dessa incompletude que nascem os deslocamentos do sujeito e do sentido na história e na sociedade (ORLANDI, 1996). E a incompletude é o lugar do possível, do perenemente inacabado; incompletos, sujeito e sentido não se fecham: são errantes, nômades e livres, por mais doloroso que possa ser.

Talvez seja ela, a abertura da incompletude, o movedor que esteja na nascença da busca humana por diversas formas de se comunicar, como se a soma das possibilidades pudesse ascender à plenitude. Daí a humanidade falar, cantar, pintar, teatralizar, cultuar, dançar, poetizar; usar a fala, a escrita, os gestos: o corpo todo (ORLANDI, 2012). E será uma dessas formas de expressão do sujeito/corpo que trataremos a partir de agora: a dança, linguagem posta em funcionamento como discurso.

A dança e a música são manifestações discursivas muito interligadas. Pode-se ouvir música sem dançar, mas raramente alguém se lança a dançar sem o ritmo da música. E assim como sua análoga, a dança se compõe de elementos organizados em sequências significativas: na música os sons, na dança os movimentos (ORLANDI, 2012). São essas sequências significativas que permitem caracterizarmos (de forma provisória) a dança como linguagem, como textualidade. A dança se discursiviza através do corpo no exato instante em que discursiviza o próprio corpo, numa relação posta como espaço-movimento-corpo, sendo o "imaginário" coletivo aquilo que organiza formas e materializa a ordem. (ORLANDI, 2012). Este texto composto por sujeito/corpo/dança se evidencia como uma formulação de sentidos; e de igual forma, e na mesma intensidade, se mostra também um meio de circulação de sentidos.

E qual é a natureza desta textualidade dançante: o deslocamento ou a suspensão? Afinal uma dança pode deslocar os sentidos sobre o corpo ou pode mais: suspender tais sentidos, jogá-los para cima e, exultante, observar seus pousos inconclusos.

\section{O CORPO QUE DANÇA A VULGARIDADE: DESLOCAMENTOS}

Ora, se a dança é uma manifestação discursiva então de forma alguma ela poderia ser única, una em intencionalidades e especificidades. Existe a dança que busca o carnaval, o salão de festas, as rodas de amigos e a liberdade de expressão e movimentos; bem como aquela dançada no palco, frente a olhares críticos, disposta a anos de ensaio e preparo.

A dança considerada vulgar é aquela da ruptura, que quebra com os sentidos impostos e resiste a qualquer coerção externa; se materializa de forma oposta à mímica, à imitação, à submissão e à obediência. O espaço da dança vulgar é igualmente insubmisso: é o lugar do desprendimento, da irreverência e da liberdade que desata o corpo do nó social (ORLANDI, 2012). Dançando, o sujeito desloca sua submissão à Formação Discursiva dominante, quebra as raízes que lhe prendem ao solo e se lança livre no desconhecido dos movimentos. A dança é deslocamento. Se antes seu corpo era alienado de si mesmo e colocado a serviço da FD dominante (corpo educado, administrado, disciplinado e normatizado), agora o sujeito se reaproxima de seu corpo e o realoca a serviço de si mesmo. A dança desloca os sentidos (e o sujeito) e inaugura uma nova forma de individuar-se; o corpo volta a pertencer ao sujeito, que o liberta para os movimentos insubmissos da dança.

A dança é o que conecta espaço, corpo e movimento, e é o sujeito quem encarna tal ligação, uma nova forma de produzir sentidos e de se significar: ruptura. Esse sujeito ainda está materialmente ligado à história e à sociedade, mas naquele momento, ainda que breve, a ideologia (que significa o corpo antes mesmo dele nascer) mostra sua face incompleta, falha e aberta às possibilidades: a dança faz deslizar o sentido de corpo. Liberdade.

Almeida \& Garcia Para uma estética da errância: o corpo, a dança e a arte 


\section{O CORPO DANÇA, O SUJEITO VOA. E O SENTIDO? SUSPENSO POR AÍ}

Existem dança e danças, e como já sinalizamos anteriormente, nos importa também aquela que se dá de forma clássica, em giros de ballet sobre palcos e ensaios. Mas sobre essa forma de dança queremos lançar outra ordem de questionamento, aliás, o principal deste artigo: quando é que a dança passa a ser arte? Os parágrafos anteriores nos mostraram que uma dança de salão, por exemplo, que desloca os sentidos do corpo/sujeito em direção à ruptura, insubmissão e liberdade, comumente não seria reclamada a priori como arte. Ora, bem sabemos que toda dança constitui uma textualidade, todavia, assim como nem todo texto se inclina para o poético, nem toda textualidade "dançante" serve-se de sentidos poéticos.

Ora, seria possível (talvez pretensioso) afirmar se a textualidade de uma dança é poética (artística) ou não? Seria possível, através desta proposta de Estética Pecheutiana (Estética da Errância), visualizarmos elementos discursivos que possibilitariam dotar de opacidade a linguagem da dança e ver se seu funcionamento se aproxima do poético ou do ideologicamente estabilizado? O método proposto neste artigo, pela Estética Pecheutiana da Errância, consiste em observar a materialidade discursiva enquanto texto (neste caso, dotar de opacidade a textualidade da dança), e analisar não seus sentidos, mas como essa textualidade se constitui como efeito de sentidos: se de forma noturna (artística), ou diurna (científica).

O corpus de análise que nos ajudará nesse percurso será Carmen (PETIT, 1949), uma ópera adaptada para ser executada por uma companhia de dança. Esta adaptação foi lançada em mil novecentos e quarenta e nove, em Londres, pela companhia de dança Les Ballets de Paris. O fragmento da peça usado neste artigo é interpretado por Alessandra Ferri e Laurent Hilaire, também sob a direção de coreografia de Roland Petit (PETIT, 2013). A ópera Carmen (BIZET, 1875) narra a história de um soldado que se vê obrigado a deixar sua amada, a cigana Carmen, para ocupar um posto de guerra distante de sua casa. Enquanto está longe, ele descobre que ela se apaixona por um toureiro, o que lhe causa grande desgosto. Existe uma textualidade primeira, o enredo de uma ópera secular, contudo, será através da dança que tais sentidos serão trabalhados. Mas como? De forma diurna e política, como a linguagem científica? Ou de forma noturna e poética, como a linguagem artística? Corpo, dança, sentidos, ensaios, falas, silêncios: contradições.

O corpo carrega significados que nasceram antes dele mesmo, o corpo. Ele recebe um nome e suas partes são decompostas noutros nomes, funções e significados fragmentados. Sentidos anteriores que desvelam a origem do sujeito: não ele, e sim dizeres mais ou menos estabilizados com valores sociais e discursos supostamente bem marcados (ORLANDI, 2012). Antes do corpo, os sentidos sobre o corpo: pés, mãos, cabeça, pescoço e corpo: todo o corpo, condicionado por nomes que tentam estabilizar lugares e efeitos ideológicos, que tentam assentar seus sentidos.

Mas eis que esse mesmo corpo, materialidade do sujeito, se lança a dançar sobre um palco, a significar numa textualidade de movimentos rítmicos. Subitamente seus pés não se parecem mais com pés, parecem dizer outra coisa. Seus braços e pernas se movem e com eles seus sentidos: lançados ao ar parecem não querer pousar. O que é que estão dizendo aqueles movimentos? O corpo parece esquecer: seu peso, seus nomes, suas antigas funções e valores. Aquele corpo parece se reinventar; movimentos de reinvenção perenemente inacabada. Nesse momento, diz Orlandi (2012), o corpo está em estado de jorro, fora do solo, fora de si. Já não é aquele sujeito primeiro que está ali: é outro, e outros, e muitos. Um fluxo contínuo de sujeitos, corpos e sentidos.

Se antes os nomes decidiam os lugares do corpo, de cada parte do corpo, agora algo novo se deu. Se até então os nomes tentavam estabilizar os efeitos ideológicos e assentar os sentidos, conferindo ordem e causalidade, agora a dança brinca com os nomes, erra e esquece: dilui aquela fina película de ordem e estabilidade que lhe mantinha estável no chão. Essa dança inaugura o corpo num acontecimento permanentemente indeciso, entre o lugar e o não lugar. É um surgir que se confunde com seu desaparecer (ORLANDI, 2012). Os braços da dançarina parecem voar, e voam. Suas pernas se confundem com as do dançarino, seus corpos se misturam e se separam, parecem dizer 'gangorras', 'berços' e 'camas', mas não se pode afirmar com certeza. Uma cabeça virou travesseiro? Tornou-se outra coisa, mas o quê? Não dá tempo de dizer: os sentidos voam, suspensos no ar: errantes. Não se diluem nem se perdem no espaço; não, eles estão ali, pousam brevemente num lugar, mas rapidamente alçam novo voo. O que acontece na dança não é discernível de sua própria retenção. Está entre o gesto e o não-gesto. Indecididos (ORLANDI, 2011, p. 3). 
Nenhum papel recruta esse corpo em movimento. Ele é o símbolo do puro surgimento, e por isso não exprime nada (ORLANDI, 2012). Aquele corpo é também símbolo, não apenas um alguém: não é só a dançarina Alessandra Ferri que está no palco, ela oferece seu corpo para o nascimento de outros sentidos e outros sujeitos. Incontáveis sujeitos e sentidos nascem naquele momento, sob os olhos dos espectadores; mas efêmeros, logo se diluem no tempo ao final de cada movimento, ao final do espetáculo.

Assim, por mais que falemos de um arranjo coreográfico fundamentado no balé clássico, com movimentos devidamente nomeados e técnicas rígidas, o foco ainda é a produção dos sentidos que uma determinada peça trabalha. A técnica sempre caminhou ao lado da arte, mas onde queremos lançar luz é sobre a linguagem que a técnica produz, se ela procura pelo estável, ou se brinca com os erros. A linguagem científica e política busca a clareza, a persuasão e a eficácia. A linguagem artística, ao contrário, não busca um sentido evidente; ela é noturna, confusa, indecisa (PÊCHEUX; GADET, 2004). É errante: não sabe de onde veio nem para onde vai. Alessandra Ferri e Laurent Hilaire, enquanto dançam, deixam de ser Alessandra e Laurent e se entregam à suspensão dos sentidos. Passam a flutuar num lugar situado no entremeio entre a razão e a loucura. Os sentidos de seus corpos deixam de ser deles, deixam de ser de alguém e passam a ser de todos. Deixam de ser um ou dois, e passam a ser mil.

\section{CONCLUSÃO}

Buscando o cuidado de não restringirmos uma definição sobre o que é a Arte, tentamos, neste artigo, dar os primeiros passos para um olhar sobre o fazer artístico através dos conceitos de Michel Pêcheux, os primeiros passos para uma estética da Errância que pressupõe a linguagem artística como um fazer discursivo que não tenta silenciar as polissemias inerentes à linguagem; ao contrário, acolhe tais errâncias de significação e brinca com os muitos sentidos, levando-os às últimas consequências.

Assim pressuposto, podemos afirmar que o corpo, enquanto dança, pode estar em busca de um deslocamento de seus sentidos ou mais: pode estar em busca de uma suspensão artística de seus sentidos. Existe dança e existem danças, logo, não há como silenciar aquela dança que busca o fazer artístico por excelência, a dança que se faz arte justamente porque brinca com as possibilidades dos sentidos, porque joga com a textualidade do corpo numa linguagem poética e noturna, errante.

E é assim que nos dispomos, através dos conceitos de Pêcheux, a olhar para uma materialidade discursiva e analisar seu caráter poético e artístico: efeitos de sentidos errantes. Assim, concluímos que existem dança e danças, e todas elas podem, ao trabalhar a textualidade do corpo, assumir um caráter poético ou ainda de entretenimento. Uma abertura estética que democratiza a arte ao invés de estabilizá-la sob a tutoria da crítica e dos jogos políticos e ideológicos.

Se não existe um lugar teórico-linguístico destacado para a poesia, o que faz distinção em uma obra de arteé, portanto, a insubmissão do sujeito da palavra em relação ao imperativo da estabilidade da língua e de sua operacionalização institucional. Brincando com as palavras, traremos para o texto o conceito de Super-Homem, de Nietzsche (2003), na intenção de exemplificar a linguagem poética da dança e demais materializações artísticas.

O Super-Homem de Nietzsche é uma das três formas com que o espírito humano se apresenta no mundo. As três transformações do espírito supõem um primeiro sujeito, o camelo, aquele que carrega nas costas o peso do trabalho, aquele que se submete às ordens e às leis, e as cumpre. O camelo é o sujeito da massa, que segue as leis da gramática e por vezes até se orgulha disso. É aquele que busca a clareza da linguagem e os sentidos estáveis. A segunda transformação se dá quando o camelo se verte em leão. O leão é o sujeito que faz as leis, que impõe ordens e faz o mundo funcionar. O leão é todo aquele que deseja domesticar a língua, que propõe sistemas e regras, que tenta solucionar os problemas da linguagem. O leão é também o sujeito político-ideológico que trabalha a estabilização dos sentidos, que apaga a possibilidade da polissemia e faz parecer que língua e mundo se correspondem. A terceira transformação é quando o leão se transforma numa criança, um ser inocente que apenas brinca no mundo. A criança é o poeta. É aquele que olha os erros da língua direto nos olhose não os teme, ao contrário: brinca com eles, joga com os sentidos e os faz errantes. 


\section{REFERÊNCIAS}

ADORNO, T. W. Textos escolhidos. Tradução Luiz João Baraúna. São Paulo: Nova Cultural, 1999.

BIZET, G. Carmen. Libreto de Henri Meilhac e Ludovic Halévy. Opéra-Comique, Paris, 1875.

COURTINE, J.-J. Metamorfoses do discurso político: as derivas da fala pública. São Carlos: Claraluz, 2006.

DIDEROT, D. Ensaios sobre a pintura. Tradução Enid Abreu Dobránszky. Campinas, SP: Papirus: 1993.

HEGEL, G. W. Cursos de estética I. São Paulo: EDUSP, 2011.

HEIDEGGER, Martin. A origem da obra de arte. Lisboa. Edições 70, 1992.

JIMENEZ, M. O que é estética? São Leopoldo, RS: Unisinos, 1999.

KANT, I. Crítica da Faculdade do juízo. Tradução Valerio Rohden e Antônio Marques. 2 ed. Rio de Janeiro: Forense Universitária, 2002.

MILNER, J. O Amor da língua. Porto Alegre: Ed. Artes Médicas Sul LTDA, 1987.

MUNIZ, F. E. Os filósofos e a arte. Rio de Janeiro: Rocco, 2010.

NECKEL, N. R. Análise de discurso e o discurso artístico. In: SEMINÁRIO DE ESTUDOS EM ANÁLISE DO DISCURSO, 2., 2005,

Porto Alegre. Anais do SEAD, Porto Alegre: UFRGS, 2005. Disponível em: <http://www.analisedodiscurso.ufrgs.br/anaisdosead/sead2.html>. Acesso em: 22 fev. 2016

NIETZSCHE, F. O nascimento da tragédia, ou Helenismo e pessimismo. Tradução, notas e posfácio J. Guinsburg. São Paulo: Companhia das Letras, 1992.

ORLANDI, E. A linguagem e seu funcionamento: as formas do discurso. Campinas: Pontes, 1996.

ORLANDI, E. P. Cidade dos sentidos. Campinas, SP: Pontes, 2004.

ORLANDI, E. P. Discurso em análise: sujeito, sentido, ideologia. Campinas: Pontes Editores, 2012.

ORLANDI, E. P. Corpo e sujeito: na dança, os sentidos. In: ENCONTRO DE ESTUDOS DE LINGUAGEM, 2011. Anais... Pouso Alegre, MG: Univás: 2011. Disponível em: <http://www.letras.etc.br/enelin2011/anais/texts/92.pdf>Acesso em: 22 fev. 2016.

Fórum linguistic., Florianópolis, v.14, n.1, p.1839-1848, jan./mar.2017. 
PETIT, R. Carmen. Ballet de Paris ë Londres 1949. Disponível em: $<$ https://www.youtube.com/watch?v=dwZkITTBTtU>. Acesso em: 20 jun. 2016.

Roland Petit, site officiel. 2013. Disponível em: $<$ http://www.roland-petit.fr/index.php?p=chore\&pc=3 >. Acesso em: 20 jun. 2016.

PÊCHEUX, M.; GADET, F. A língua inatingível. O discurso na história da linguística. Campinas: Pontes, 2004.

SANTOS, E. I. d. Modernization and its discontents: discourses on the transformation of caipira into sertanejo music. Vibrant: Virtual Brazilian Anthropology, Brasília, v. 8, p. 291-321, 2011. ISSN 1809-4341. Disponível em:

< http://www.scielo.br/scielo.php?script=sci_arttext\&pid=S1809-43412011000100011\&nrm=iso >. Acesso em: 22 fev. 2016. 